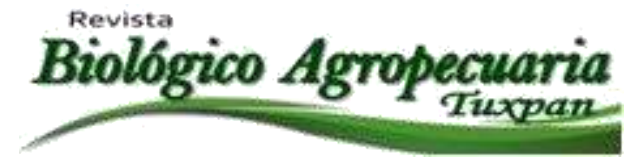

\title{
Visión General del Marco Jurídico-Económico para analizar las Políticas Públicas en el sector de los Agronegocios en México bajo el contexto de Globalización
}

Economic Overview-Legal Framework for analyzing public policies in the field of Agribusiness in Mexico under the context of globalization
Martínez-Sánchez César E. ${ }^{\circledR}$, Roberto De Luna-Ramírez ${ }^{1}$, Oralia Elorza-Martínez ${ }^{1}$ y Sara A. Alarcón-Pulido ${ }^{1}$.

${ }^{1}$ Facultad de Ciencias Biológicas y Agropecuarias. Universidad Veracruzana. Carrt. Tuxpan-Tampico Km. 7.5. Tuxpan; Veracruz; México. El: 017838344350.

${ }^{凶}$ Autor para correspondencia: cesamartinez@uv.mx

Recibido: $17 / 01 / 2014$

Aceptado: 29/07/2014

\section{RESUMEN}

Este artículo describe a la globalización como una realidad que México atraviesa de manera vertical y horizontal en los sectores productivos, sociales económicos, así como el sector de los Agronegocios. Citandose que existe una normatividad jurídico-económica que permite la elaboración de políticas públicas para aumentar la competitividad internacional de los Agronegocios mexicanos. Pero que sin embargo se podrían establecer propuestas evolucionadas que integren conceptos de política social (salud, educación, vivienda y empleos) que promuevan y estimulen al productor así como teorías de las instituciones con las tendencias del neoinstitucionalismo que brinden mayor poder al Estado de establecer las condiciones de producción, financiamiento, transparencia. Dichas instituciones deberán forjar el futuro de los Agronegocios en México ya que establecerían la sinergia del poder Estatal y las tendencias internacionales de organización.

Palabras Clave: Globalización, Marco jurídico - económico, Políticas públicas, Agronegocios.

\begin{abstract}
This article describes to globalization as a reality that Mexico traverses of vertically and horizontally in productive sectors, social economic, well as the sector of Agribusiness. Citing that there is a legal and economic regulations allowing public policy to increase the international competitiveness of Mexican Agribusiness. But that could be established yet evolved proposals that integrate concepts of social policy (health, education, housing and jobs) to promote and encourage the producer as well as theories of institutions neoinstitutionalism trends that provide more power to the State to establish the
\end{abstract}


conditions of production, financing, transparency. These institutions will shape the future of Agribusiness in Mexico as to establish the synergy of State and international organization trends.

Keywords: Globalization, Legal framework - economic, Public Policy, Agribusiness

\section{INTRODUCCIÓN}

México se encuentra inmerso en un fenómeno de constante integración económica, cultural, política y social llamado globalización. José Manuel García, en su obra La globalización Económica, define este concepto como:

La globalización es el resultado de las políticas económicas nacionales determinadas por motivos muy diversos como fueron las

circunstancias adversas derivadas del agotamiento de la fase expansiva del ciclo económico de la posguerra mundial, el inevitable ajuste de los sistemas productivos a las nuevas condiciones del abastecimiento energético, o la toma de conciencia sobre la finitud de determinados recursos naturales que cuestionaban el sostenimiento del sistema. Se buscó en la economía internacional soluciones a los problemas del empleo y crecimiento económico, rompiendo la perspectiva de la economía nacional, dominante, creando nuevas condiciones para la acumulación.

Así entendemos la globalización como un proceso obligado por el cual los países debían atravesar para subsanar los estragos del pasado, así como un esfuerzo sin precedente para establecer políticas internas equiparables con el marco legal internacional que estaba surgiendo durante el periodo posguerra.

Existen también otras definiciones de globalización basadas en la evolución del proceso globalizador en la práctica cotidiana. Diferentes autores identifican sus efectos y establecen conceptos adecuados desde diversas perspectivas. Por ejemplo la globalización desde la perspectiva de países subdesarrollados, en el cual entraría México:

"Para un número de pueblos poco evolucionados, la globalización es un concepto que se basa en la competición libre, para avanzar en el trabajo y en la producción, como una forma de progreso y alegan que sólo un sistema basado en la cooperación y no en la competición, puede progresar y procurar la igualdad más equilibrada y la solidaridad entre los pueblos".

Bajo este concepto, la globalización parecer ser vista como una imposición del exterior, una ventaja competitiva desarrollada por países industrializados para explotar bienes en su nombre en el exterior, utilizando instrumentos como cooperación internacional o establecimiento de relaciones comerciales internacionales como Tratados, Acuerdos, etc. Cualquier definición es válida y adecuada desde el punto de vista del que se analice. El hecho es que México es un jugador más en el campo de la globalización y que por lo tanto se debe seguir esta tendencia para no salir del juego para crecer y desarrollarse económicamente

Con lo anterior se debe entender como está conformado el Estado Mexicano para después analizar la estructura de políticas públicas aplicadas al sector dentro de un ambiente en constante cambio e integración debido al fenómeno de la globalización. Asi como la compleja relación entre la gente del campo, esto para lograr una correcta organización que permita el desarrollo de ventajas competitivas eficientes que, bajo la

\section{Revista Científica Biológico Agropecuaria Tuxpan 2 (1) ISSN: 2007-6940}


coyuntura de globalización, accesos a mercados y competencia internacional, permitan al Agro Mexicano tomar un lugar de referencia de calidad, precio e innovación.

Dicho juego de interconexión internacional exige a sus jugadores reglas de entrada y participación. Es así como México establece un marco Jurídico-Económico equiparable con la normatividad internacional que le hace miembro activo y legal de la globalización.

\section{MATERIALES Y MÉTODOS}

Este trabajo de investigación consistió en la recopilación bibliográfica para apoyar el marco referencial y marco teórico sobre el fenómeno de la globalización y su análisis conceptual sobre el neoliberalismo imperante en el mundo actual y su efecto en los agronegocios. Apoyándose en tres tipos básicos de fuentes de información: Fuentes primarias (directas), obteniendo datos de primera mano (libros, antologías, monografías). Fuentes secundarias (resumen y listado de referencias en un área de conocimiento en especial). Así como las Fuentes terciarias (apoyándose de revistas, conferencias, simposios).

\section{RESULTADOS Y DISCUSIONES}

Después de este análisis se destaca que el sector agropecuario mexicano es la base fundamental para el desarrollo nacional. Es por esto que exige especial atención al momento de analizar y proponer políticas públicas eficaces.

Determinándose que el estado mexicano consta de cuatro elementos fundamentales que definen su existencia, estos son Población, que como mencionan Jesús Santillán y Juan Luis Cervantes en su artículo "El Estado Mexicano Moderno", es el elemento humano del estado y que son sujetos de derechos y obligaciones reguladas en los artículos 30 al 38 constitucionales.

También es elemento del estado el Territorio que está delimitado en los artículos 40, y 43 al 48 constitucionales y que se refieren a su delimitación geográfica y política. De la misma manera, el otro elemento integrador del estado, es el poder público que en el artículo 39 constitucional hace referencia a este como la soberanía nacional que reside esencial y originalmente en el pueblo y que éste, según el artículo 40 y 41 es capaz de constituir el tipo de gobierno que así decida y que esta soberanía la ejerce por medio de los Poderes de la Unión. Cómo último elemento está el bien común, que según Santillán y Cervantes, es el fin último del Estado y que básicamente establece que todo poder público dimana del pueblo y se instituye para su propio beneficio. El poder público mexicano está integrado por un poder legislativo, un poder ejecutivo y un poder judicial. Lo que nos constituye como República representativa, democrática y federal (Artículo 39 constitucional).

En cuanto a la interconexión internacional esta, exige a sus jugadores reglas de entrada y participación. En este contexto identificamos la normativa constitucional en materia económica que va acorde al sistema de apertura comercial y libre mercado que México adopta en el Neoliberalismo en la década de los 80’s (Montalvo, 2008).

El análisis económico constituye el estudio de la eficiencia de políticas públicas que en materia de Agronegocios se establecen en México, entendiendo estas como las que surgen del Plan Nacional de Desarrollo y a su vez los programas sectoriales. Lo anterior con fundamento en el artículo 28 y que contempla el área de los Agronegocios en el párrafo a continuación: 
La ley establecerá los mecanismos que faciliten la organización y la expansión de la actividad económica del sector social: de los ejidos, organizaciones de trabajadores, cooperativas, comunidades, empresas que pertenezcan mayoritaria o exclusivamente a los trabajadores y, en general, de todas las formas de organización social para la producción, distribución y consumo de bienes y servicios socialmente necesarios.

Así mismo, vivimos bajo un sistema de planeación democrática lo que debe propiciar al sector de los Agronegocios en México desarrollarse bajo esquemas de participación ciudadana que permitan exponer propuestas de los diversos sectores bajo una sinergia, como el económico, social y cultural y a través de ellos lograr una planeación sólida, dinámica y con equidad que impulse el crecimiento de la economía.

Todo esto bajo esquemas que cumplan los fines del proyecto nacional expuestos en el artículo 26 constitucional. Donde es indispensable la participación del Ejecutivo para que establezca los sistemas de planeación democrática que conlleven el desarrollo Agro en México. Dichos sistemas de planeación deben incluir programas de desarrollo específicos y con alta coordinación entre los tres niveles de gobiernos, y sobre todo, que concreticen las acciones acordadas así como el análisis de sus resultados para las adecuaciones correspondiente.

Se debe tener claro que se vive en un México polarizado. En opinión de algunos autores como José Ayala Espino y Miguel Ángel Rivera Ríos nuestro país está dividido, es decir, existen dos países en un mismo territorio y con el mismo nombre. El norte se encuentra desarrollado, mientras el sur sufre de un marcado retraso social y económico, por lo que es primordial que al momento de establecer propuestas de políticas públicas para desarrollar el sector Agropecuario en México y para así llevar esos productos terminados y tecnificados al mercado a través de procesos de negociación y comercialización, estas deben ser integrales e igualmente aplicables en todo el territorio, ya sea físico y político (artículos 42-48 constitucionales).

También sería necesario integrar en las propuestas de políticas públicas la reglamentación necesaria para el uso adecuado del recurso público a través de los sistemas de rendición de cuentas, así como de sistemas de financiamiento eficiente y la expedición de leyes que promuevan el desarrollo de instituciones de investigación científica especializada en Agronegocios bajo el amparo del artículo 73 constitucional. Así como que la administración de estos recursos debe ser con eficiencia, economía, transparencia y honradez para satisfacer los objetivos a los que estén destinados, y que a su vez, su aplicación deberá ser evaluada para propiciar que los recursos económicos sean debidamente asignado tal como lo marca el artículo 134 constitucional.

Por otro lado, al hablar de desarrollo de competencia internacional a través de políticas públicas del sector de Agronegocios bajo el esquema de la rectoría nacional del Estado Mexicano, forzosamente deberíamos adecuar estas políticas al marco normativo de la Ley de Comercio Exterior que tiene por objeto: "regular y promover el comercio exterior; incrementar la competitividad de la economía nacional; propiciar el uso eficiente de los recursos productivos del país; integrar adecuadamente la economía mexicana con la internacional, defender la planta productiva de prácticas desleales del comercio internacional y contribuir a la elevación del bienestar de la población".

\section{Revista Científica Biológico Agropecuaria Tuxpan 2 (1)} ISSN: 2007-6940 
Se observa la integración de elementos fundamentales para el desarrollo, tales como elevación del bienestar de la población, esto a través de fomento a la producción y comercio justo que brinden al productor las condiciones necesarias para crear una oferta internacional y que fluya de manera adecuada por las vías jurídicas-comerciales.

El sector de los Agronegocios en México necesita de instituciones creadas por el Estado que sean capaces de contener los efectos de la globalización y convertirlos en ventajas competitivas del país. Pero esto no podría ser llevado a cabo sin una restructuración institucional federal, es decir, la implementación del Neoinstutcionalismo económico que valora "La necesidad de no ver al mercado como ente único sino que debe interactuar de manera integral con los sistemas políticos, educativos y sociales que solamente proporciona el Estado" (Ayala, 1999). Dichas instituciones deberían ser políticamente activas para que de manera simultánea propongan un marco de propuestas aplicables al sector, tal como lo marca el artículo 11 constitucional.

La fortaleza del neoinstitucionalismo recae también en que éste acentúa la importancia de las estructuras de poder $y$ organizaciones políticas: "Estado es una institución relevante en el intercambio porque genera incentivos o desincentivos a la inversión, trabajo y el ahorro. El estado es el generador más importante de instituciones" (Ayala, 1999).

En este sentido se entiende que el mercado no es quien establece las condiciones, tal y como lo da entender el modelo de economía de mercado en el que se vive, sino que al contrario regresa al Estado como máxima autoridad y como el ente que permite que las condiciones de mercado sean adecuadas. Todo esto con instituciones capaces de adecuarse al ambiente globalizado en el cual se desarrollan las economías hoy en día.

\section{CONCLUSIONES}

El sector de los Agronegocios en México exige una normativa adecuada para competir en mercados internacionales, por lo que sería necesario remitirnos a la Ley Federal de Competencia que tiene como objeto: "Proteger el proceso de competencia y concurrencia, mediante la prevención y

eliminación de monopolios, prácticas monopólicas y demás restricciones al funcionamiento eficiente de los mercados de bienes y servicios" Dicha política de competencia se entiende como la rivalidad ente empresas que operan en un determinado sector de la actividad económica para captar la mayor cuota del mercado posible, ofreciendo mejores precios, bienes y servicios.

"Dicha política de competencia se entiende como la rivalidad ente empresas que operan en un determinado sector de la actividad económica para captar la mayor cuota del mercado posible, ofreciendo mejores precios, bienes y servicios. También debería servir para procurar la difusión del poder económico (Montalvo, 2008).

Todo esto para estimular las mejores prácticas de manufactura y certificaciones adecuadas para ser preferidos por otros mercados en el exterior y salir de la inercia de ser productores masivos de materia prima de baja calidad que en vez de generar desarrollo, causa conformidad y atraso. Pero sobre todo de proteger al sector de un fenómeno que existe, que es el de los monopolios y prácticas monopólicas de algunas empresas extranjeras y nacionales establecidas en el país que acaparan parte de la demanda internacional y que castigan a los pequeños productores para que tengan que venderles materia prima barata y sin 
esquemas de pago adecuados que incentiven la producción. Así también se podrían hacer respetar las disposiciones establecidas en la Ley de Inversión Extranjera en cuanto al porcentaje de participación del capital foráneo en la industria nacional.

\section{LITERATURA CITADA}

Ayala, E. J. 1999. Instituciones y Economía, Fondo de Cultura Económica, $1^{\mathrm{a}}$ ed., México.

Ginebra, S., X. 1997. Las Alianzas Estratégicas o Joint Ventures y el Derecho de la Competencia, Revista de Investigaciones jurídicas, núm.21, año 21, Escuela Libre de Derecho, México. https://doi.org/10.1163/15718190019684343

Montalvo, R. T. 2008. La Estatalidad Económica Mexicana VS el Marco Económico Regional. Democracia y Políticas Públicas, Universidad Michoacana de San Nicolás de Hidalgo. Facultad de Derecho y Ciencias Sociales. $1^{a}$ ed.,p. 179. Morelia, 2008. https://doi.org/10.21041/conpat2019/v2pat142

Ribeiro, M. F., Montalvo, R. T., Da Cunha L.

T. y Morillo-Velarde, L. M. 2008.

Democracia y Políticas Públicas, Universidad Michoacana de San Nicolás de Hidalgo. Facultad de Derecho y Ciencias Sociales. $1^{a}$ ed., Morelia, 2008. https://doi.org/10.21041/conpat2019/v2pat142
Rivera, R. M. A. 2000. México en la Economía Global, Jus, $1^{\text {a }}$ ed., México.

Montalvo, R. T. 2008. El Derecho Económico en los Flujos Comerciales, Arana, $1^{\mathrm{a}}$ ed., México.

Santillán, G. J. y Cervantes, A.J. L. 2008. El estado Mexicano Moderno: Un Acercamiento a su Estructura y Función. Democracia y Políticas

Martínez et al., 2014. Públicas, Universidad Michoacana de San Nicolás de Hidalgo. Facultad de Derecho y Ciencias Sociales $1^{\mathrm{a}}$ ed.,p.145. Morelia.

https://doi.org/10.21041/conpat2019/v2pat142

Sheahan, J. 1990. Modelos de Desarrollo en América Latina, Alianza, $1^{\mathrm{a}}$ ed., México.

Trigo, C. M. 2004. Multinacionales, Globalización y Terrorismo, Visión Net, $1^{\mathrm{a}}$ ed., España.

Copyright (c) 2014 César Enrique Martinez Sánchez, Roberto De Luna Ramirez, Oralia Elorza Martinez y Sara Aida Alarcón Pulido

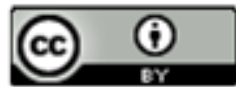

Este texto está protegido por una licencia Creative Commorr 4.0 .

Usted es libre para Compartir —copiar y redistribuir el material en cualquier medio of ormato- y Ad aptar el documento —remezclar, transformar y crear a partir del material - para cualquier propósito, inchso para fines comerciales, siempre que cumpla la condición de:

Atribución Usted debe dar crédito a la obra original de manera adecuada, proporcionar un enlace a la licencia, e indicar si se han realizado cambios. Puede hacerlo en cualquier forma razonable, pero no de forma tal que sugiera que tiene el apoyo del licenciante olo recibe por el usoque hace de la obra.

Resumendelicencia - Textocompletodelalicencia 